\title{
Effect of Co-solvents on Transesterification of Refined Palm Oil in Supercritical Methanol
}

\author{
Narupon Jomtib ${ }^{1}$, Chattip Prommuak ${ }^{1}$, Motonobu Goto ${ }^{2}$, Mitsuru Sasaki ${ }^{2}$, \\ and Artiwan Shotipruk ${ }^{1, *}$
}

1 Department of Chemical Engineering, Faculty of Engineering

Chulalongkorn University, Patumwan, Payathai, Bangkok, 10330, Thailand

2 Department of Applied Chemistry and Biochemistry, Kumamoto University,

Kumamoto 850-8555, Japan

E-mail: artiwan.sh@chula.ac.th

Abstract. This study examined the non-catalytic transesterification of refined palm oil, using supercritical methanol as a solvent with and without the presence of co-solvent, i.e. toluene, benzene, or hexane. Without the presence of a co-solvent, methyl esters can be produced via the non-catalytic transesterification of palm oil at $300^{\circ} \mathrm{C}$, using a methanol to oil molar ratio of $45: 1$, with $89.4 \%$ conversion achieved after $50 \mathrm{~min}$. The reaction performance could be improved by adding either benzene or toluene (with $10 \% \mathrm{v} / \mathrm{v}$ solvent to oil) as co-solvent to 92.1 and $95.1 \%$, respectively, while reducing the required amount of excess methanol from 45:1 to 25:1. Under most conditions, the conversion of palm oil decreased with the addition of hexane due to its antisolvent properties.

Keywords: Biodiesel, palm oil, supercritical, methanol, transesterification, co-solvents.

ENGINEERING JOURNAL Volume 15 Issue 3

Received 10 March 2011

Accepted 15 May 2011

Published 1 July 2011

Online at http://www.ej.eng.chula.ac.th/eng/

DOI:10.4186/ej.2011.15.3.49 


\section{Introduction}

As the demand and price of diesel fuel has been increasing rapidly over the past few years, the use of biodiesel as an alternative renewable fuel is receiving increased attention. Biodiesel is generally produced via the transesterification reaction, in which the triglycerides in vegetable oil react with alcohol converting into esters of fatty acids (biodiesel) and glycerol in the presence of either alkali or acid catalysts. As for alkali catalyzed process, the rapid reaction rate can be achieved but the major limitation is that the alkali catalyst can easily react with free fatty acid in vegetable oil and form soap, which makes it difficult to separate glycerol from methyl esters product. On the other hand, by applying acid catalyst, no soap formation occurs, however the process has been reported to be much slower than that of the alkali catalyzed process [1-2]. In addition, small amounts of water present in the reaction mixture can be problematic since acid tends to react with water resulting in significant catalytic deactivation. It is noted that the major limitation for both acid and alkali catalyzed reactions is the difficulty in recovering and treating the catalyst, resulting in large amounts of wastewater and an increase in the overall cost of the process.

As an alternative procedure, the transesterification in subcritical and supercritical alcohol has been proposed as a fast and environmentally friendly method for biodiesel production. Soybean oil, rapeseed oil, and sunflower oil have previously been used as the feedstock for this reaction [3-8]. Kinetics studies of rapeseed and soybean oil transesterification in subcritical and supercritical methanol have also been reported [7-8]. Benefits of this non-catalytic process include the reduced reaction times and simpler purification procedures. However this process also needs high temperatures and pressures to reach the supercritical state; as such studies have been carried out to investigate methods of reducing the energy demands of this process.

Cao et al. (2005) [4] investigated the transesterification reaction of soy bean oil in supercritical condition by using propane as a co-solvent. They reported that, in the presence of propane, the reaction rate constant for transesterification increased markedly, which could be due to the formation of a single phase in the reaction system. As a result, reductions in operating temperature, pressure and molar ratio of alcohol to vegetable oil were achieved. From these experiments, the reported optimal temperatures, methanol to oil molar ratio and propane to methanol ratio were $280^{\circ} \mathrm{C}, 24: 1$, and 0.05 , respectively. In addition to propane, supercritical carbon dioxide was also tested as a potential co-solvent [4]. The results showed the optimal reaction conditions to be a temperature of $280^{\circ} \mathrm{C}$, a methanol to oil ratio of 24:1, and a $\mathrm{CO}_{2}$ to methanol ratio of 0.1:1.

Focusing on the type of feedstock for biodiesel production, currently, refined palm oil is the major feedstock for biodiesel production in Thailand; and the alkali-catalyzed transesterification process (with $\mathrm{NaOH}$ ) is most commonly applied in its production facilities. However, in an effort to minimize the industries impact upon the natural environment, a reduction in waste from biodiesel production is of increasing priority. Transesterification of palm oil in supercritical methanol has been studied in which the effect of various parameters such as temperature $\left(200-400^{\circ} \mathrm{C}\right)$, molar ratio of methanol to palm oil (3-80), and reaction time (0.5-20 $\mathrm{min})$ were determined [9]. This current work aims to investigate the effects of co-solvents i.e. toluene, benzene and hexane on the production of transesterification of refined palm oil in a non-catalytic supercritical methanol process. Hexane was chosen as a co-solvent since it is a solvent for vegetable oil extraction. Benzene and toluene are aromatic hydrocarbons, commonly used as solvents in various industries. In addition, for the conditions used for non-catalytic transesterification in this study, these co-solvents are non-reactive. In addition, due to the high volatilities of these compounds, they can be easily separated from the biodiesel products rather and can be recycled. Here, the effect of operating conditions such as reaction time, temperature, and methanol to refined palm oil molar ratio and concentration of co-solvent to palm oil, on the conversion were reported.

\section{Experimental}

\subsection{Materials}

Refined palm oil used in this study was supplied by Chumporn Palm Oil Industry Public, Co, Ltd, Thailand. The fatty acid profile of the oil sample is shown in Table 1. Methyl ester standards (methyl 
palmitate, methyl stearate and methyl oleate) were purchased from Wako Chemicals, Japan. Methanol and hexane (analytical grade) was purchased from Fisher scientific, UK.

\begin{tabular}{llll}
\hline Fatty acid & $\begin{array}{l}\text { Composition } \\
(\boldsymbol{\%} \mathbf{w t})\end{array}$ & Fatty acid & $\begin{array}{l}\text { Composition } \\
(\boldsymbol{\%} \mathbf{w t})\end{array}$ \\
\hline Palmitic acid & 45.6 & Tetracosenoic acid & 0.6 \\
Oleic acid & 33.3 & Linolenic acid & 0.3 \\
Linoleic acid & 7.7 & Ecosanoic acid & 0.3 \\
Stearic acid & 3.8 & Ecosenoic acid & 0.2 \\
Myristic acid & 1.0 & Palmitoleic acid & 0.2 \\
\hline
\end{tabular}

Table 1. Fatty acid profile in refined palm oil sample.

\subsection{Supercritical methanol transesterification}

Experiments were carried out using an $8.8 \mathrm{ml}$ stainless steel batch-type reactor and an electric furnace (AKICO, Japan). Prior to the experiment, the temperature of the electric furnace at the location of the furnace adjacent to the reactor was controlled at the desired reaction temperature $\left(250^{\circ} \mathrm{C}\right.$ or $\left.300^{\circ} \mathrm{C}\right)$. To carry out the transesterification of palm oil in supercritical methanol, the reactor was charged with the mixture of methanol and oil at ratios ranging between $6: 1$ and 45:1, respectively. The reaction vessel was placed into the furnace and was heated to the set temperature, which takes approximately $15 \mathrm{~min}$, after which the reaction continued for a time period (ranging from 10 to $60 \mathrm{~min}$ ). The whole system (furnace heater and reactor) was placed onto a rotary shaker which allowed for proper mixing during the reaction. In order to determine the effect of the co-solvents on the reaction performance, various concentrations of hexane, benzene and toluene (10 to $50 \% \mathrm{v} / \mathrm{v})$ were added along with palm oil and methanol. It should be noted that, for the reaction conditions employed in our study, the GC analysis confirmed that there was no reactivity between the co-solvents and palm oil (data not shown).

The pressure of the reaction was measured to be between 10 and $15 \mathrm{MPa}$. After completion of the set time period, the vessel was removed from the heat source and placed into a water bath to reduce the temperature and cease the reaction. The reaction products were discharged from the reactor and allowed to settle and separate into three layers. The top phase was the unreacted methanol, which was removed by evaporation. The remaining upper and lower phases were methyl esters (biodiesel) and glycerol, respectively, and their separation was performed by gravimetric precipitation due to the small amount of the biodiesel sample.

\subsection{Analysis}

The amount of methyl esters in the reaction products diluted in hexane was analyzed by gas chromatography (GC) (Shimadzu 14B, Japan) using an Rtx 5 column ( $30 \mathrm{~m}, 0.25 \mathrm{~mm} \mathrm{ID}, 0.25 \mu \mathrm{m})$ and a flame ionization detector (FID). The oven temperature profile was as follows: start at $150^{\circ} \mathrm{C}(2 \mathrm{~min})$, ramp at $5^{\circ} \mathrm{C} \min ^{-1}$ to $250^{\circ} \mathrm{C}$ (5 min). Each sample was prepared for $\mathrm{GC}$ analysis by adding $6 \mathrm{ml}$ of $\mathrm{n}$ hexane to $0.1 \mathrm{ml}$ of biodiesel product with eicosane as an internal standard. Two microlitres of this sample were injected into the column. The methyl ester conversion was estimated by Eq. (1).

$$
\% \text { conversionof methylester }=\frac{W_{F A M E s, \text { actual }}}{W_{\text {FAMEs, theory }}} \times 100
$$

Where $W_{\text {FAMEs,actual }}$ and $W_{\text {FAMEs, theory }}$ are actual weights of FAMEs $(\mathrm{g})$ and theoretical weights of FAMEs (g), calculated assuming a $100 \%$ conversion of the starting palm oil, respectively.

\section{Results and discussion}

\subsection{Transesterification of refined palm oil in supercritical methanol}


The transesterification of refined palm oil in supercritical methanol was carried out under several operating conditions i.e. refined palm oil to methanol molar feed ratio, reaction temperature, and reaction time. Details of these experiments are presented below:

\subsubsection{Effect of methanol to palm oil molar ratio}

Stoichiometrically, three moles of alcohol and one mole of triglyceride are required to produce three moles of methyl esters and one mole of glycerol. An excess amount of alcohol is also required to ensure near complete conversion of the triglycerides. However, this can lead to increased production costs, thus, the effect of the methanol to reactant molar ratio on the conversion of palm oil was investigated by varying the molar ratio from 6:1 to $45: 1$ (at the reaction time of $50 \mathrm{~min}$ and reaction temperatures of $250^{\circ} \mathrm{C}$ and $300^{\circ} \mathrm{C}$ ).

The results in Fig. 1 show that the conversion of palm oil increased with increasing methanol to palm oil molar ratio and operating temperature. Typically, excess methanol was required to shift the equilibrium of the reversible transesterification reaction to the right. The high molar ratio of methanol also provides better opportunity for methanol molecules to contact with triglyceride molecules during the reaction. Compared with the transesterification reaction with alkali catalyst, in which the optimal methanol to oil ratio was reported to be 6:1 [10], the result for transesterification under supercritical conditions from this study indicated that a higher ratio of methanol is required. This result is in good agreement with the literatures [5, 7, 8], which could be explained by considering the critical temperature of the methanol and oil mixture. The reactant mixture critical temperature could be calculated by first assuming oil is a single pseudo-triacylglyceride according to the study by Espinosa et al., 2002 [11], which allows the calculation of critical properties of the oil of interest to be determined using Lydersen's method of group contributions. The critical point of methanol and palm oil mixture can then be calculated using Lorentz-Berthelot-type mixing rules [12].

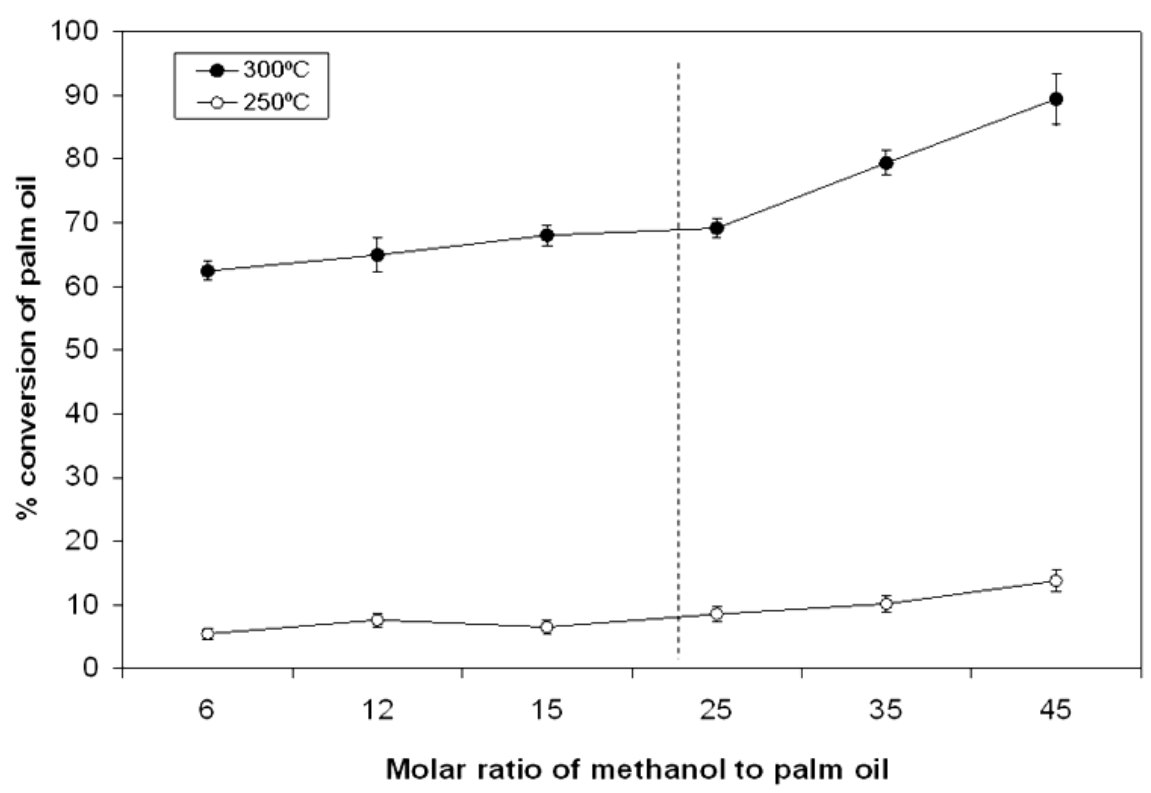

Fig. 1. Effect of the molar ratios of methanol to palm oil on conversion of palm oil at 250 and $300^{\circ} \mathrm{C}$, reaction time of $50 \mathrm{~min}$.

Table 2 presents critical temperature for various mixtures of methanol and palm oil. At the highest methanol to palm oil ratio $(45: 1)$, the critical temperature was estimated to be $280^{\circ} \mathrm{C}$. Thus, the operating temperature of $250^{\circ} \mathrm{C}$ was too low to reach supercritical state; the conversion was then observed to be low for all molar ratio studies. It is noted that, at this temperature, the conversion was limited by the temperature of the reaction and the effect of the methanol to oil molar ratio was insignificant. On the other hand, at the reaction temperature of $300^{\circ} \mathrm{C}$, the critical state could be 
achieved when the ratio of methanol to oil was as low as 24:1. As such, at this temperature, the supercritical state could be achieved for ratios of 24:1 and higher, thus the increase of the methanol to oil molar ratio allowed noticeable increases in the conversion of palm oil. It should be noted however that compared to existing report $[5,8,9]$, the reaction time in this study is relatively high. This might be due to the rather low reaction temperature with the maximum temperature of $300^{\circ} \mathrm{C}$ being employed due to the equipment limitation. Although, according to TGA study of palm oil under nitrogen atmosphere, the degradation of palm oil was reported to start at around $280^{\circ} \mathrm{C}$ and that the maximum degradation rate takes place at $381{ }^{\circ} \mathrm{C}$ [13]. Other studies may have been able to carried out the reactions at higher temperature since the reaction time could be greatly reduced, such that the degradation had not taken place significantly.

\begin{tabular}{llllll}
\hline Molar ratio & $\mathbf{T}_{\mathbf{c}}(\mathbf{K})$ & $\mathbf{T}_{\mathbf{c}}\left({ }^{\mathbf{}} \mathbf{C}\right)$ & $\left.\mathbf{P}_{\mathbf{c}} \mathbf{( M P a}\right)$ & $\mathbf{V}_{\mathbf{c}}(\mathbf{L} / \mathbf{m o l})$ & $\mathbf{Z}_{\mathbf{c}}$ \\
\hline $45: 1$ & 554.24 & 281.24 & 6.77 & 0.15 & 0.22 \\
$35: 1$ & 563.38 & 290.38 & 6.46 & 0.16 & 0.22 \\
$25: 1$ & 577.77 & 304.77 & 5.98 & 0.18 & 0.22 \\
$15: 1$ & 604.18 & 331.18 & 5.11 & 0.22 & 0.23 \\
$12: 1$ & 617.24 & 344.24 & 4.69 & 0.25 & 0.23 \\
$6: 1$ & 662.22 & 389.22 & 3.37 & 0.37 & 0.23 \\
\hline
\end{tabular}

Table 2. Critical properties of palm oil and methanol mixture at various compositions.

\subsubsection{Effect of reaction temperature and time}

Figure 2 and 3 show the effects of reaction temperature $\left(250,280\right.$ and $\left.300^{\circ} \mathrm{C}\right)$ and reaction time on the conversion of palm oil at two different methanol to oil molar ratios (45:1 and 25:1). Clearly, the conversion of palm oil increased with increasing reaction temperature and time for both methanol to oil molar ratios of 25:1 and 45:1. By using the methanol to oil molar ratio of 45:1 and a reaction time of 80 min, the conversion of palm oil increased (from 28.9 to 93.7 and $95.3 \%$ ) with increasing reaction temperature (from 250 to 280 and $300^{\circ} \mathrm{C}$, respectively). By using the methanol to oil molar ratio of 25:1, the conversion ratio of palm oil was significantly lower than that at the methanol to oil molar ratio of 45:1.

When the reaction temperature increases, the degree of hydrogen bonding decreases, thus the polarity of the alcohol decreases, and has increased hydrophobic nature with the lower dielectric constant. As a result, non-polar triglycerides can dissolve in the supercritical alcohol more readily to form a single phase of triglyceride and methanol mixture. When the temperature of the reaction exceeds the critical temperature of the reaction mixture, methanol and oil form a single supercritical fluid phase. At this condition, the rate of reaction increased considerably and therefore the near complete conversion of the triglycerides could be achieved. 


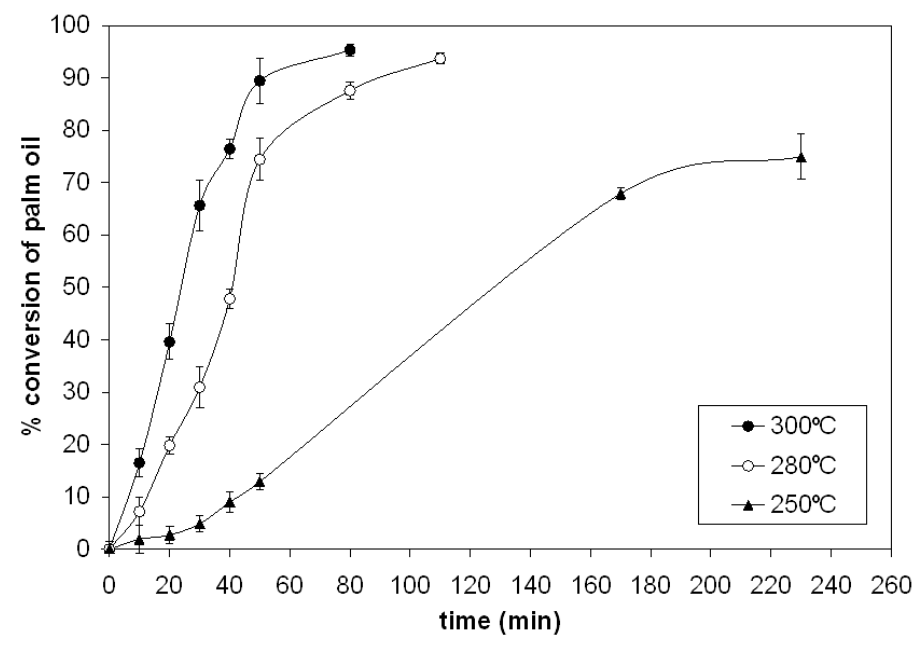

Fig. 2. Effect of the reaction temperature on conversion of palm oil at molar ratio of methanol to palm oil of 1:45.

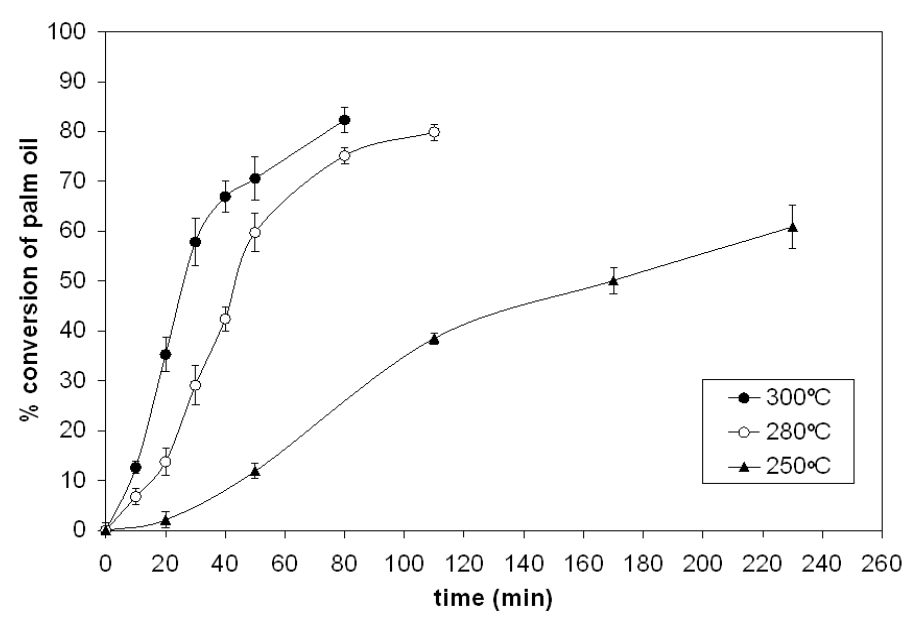

Fig. 3. Effect of the reaction temperature on conversion of palm oil at molar ratio of methanol to palm oil of 1:25.

\subsection{Transesterification in supercritical methanol in presence of co-solvent}

To enhance the higher efficiency for the transterification of refined palm oil in supercritical methanol, the effect of the co-solvent addition was evaluated. Previously, it was reported that the uses of propane and $\mathrm{CO}_{2}$ as co-solvents resulted in the reduction of the required reaction temperature to be about $280^{\circ} \mathrm{C}$ [4]. This is due to a reduction in the critical temperature of the oil and methanol mixture to approximately $260^{\circ} \mathrm{C}$ with the addition of propane $\left(\mathrm{T}_{\mathrm{c}}=96.67^{\circ} \mathrm{C}\right.$ and $\left.\mathrm{P}_{\mathrm{c}}=4.20 \mathrm{MPa}\right)$ and $\mathrm{CO}_{2}\left(\mathrm{~T}_{\mathrm{c}}=31.0^{\circ} \mathrm{C}\right.$ and $\mathrm{P}_{\mathrm{c}}=7.28 \mathrm{MPa}$ ). In this study, hexane, benzene and toluene were used as co-solvents and the effect of co-solvent to oil concentrations ( 10 to $50 \% \mathrm{v} / \mathrm{v})$ on the formation of methyl esters was determined. In these experiments, transesterification of palm oil was carried out by using a methanol to oil molar ratio of $45: 1$, a reaction temperature of $300^{\circ} \mathrm{C}$ and reaction time of $50 \mathrm{~min}$.

The results in Fig. 4 indicate that the conversion of palm oil slightly increased from $89.4 \%$ (without addition of solvent) to 92.1 and $95.1 \%$ when benzene and toluene (with $10 \% \mathrm{v} / \mathrm{v}$ solvent to oil) were present. Nevertheless, at higher contents of benzene and toluene (20 to $50 \% \mathrm{v} / \mathrm{v}$ solvent to oil), the conversion of palm oil decreased steadily with increasing benzene and toluene contents. The increased conversion with the addition of benzene and toluene could be attributed to the solubility of vegetable oil within these solvents as well as their miscibility with methanol. Although at supercritical state, the mixture would be in a single phase, however the system in this study was pressurized only by heating the oil and methanol mixture in a closed vessel without applying additional pressure, thus pressure 
might not have reached the mixture critical value. The co-solvents are therefore expected to assist in the mixing of methanol and oil in the reactor [14].

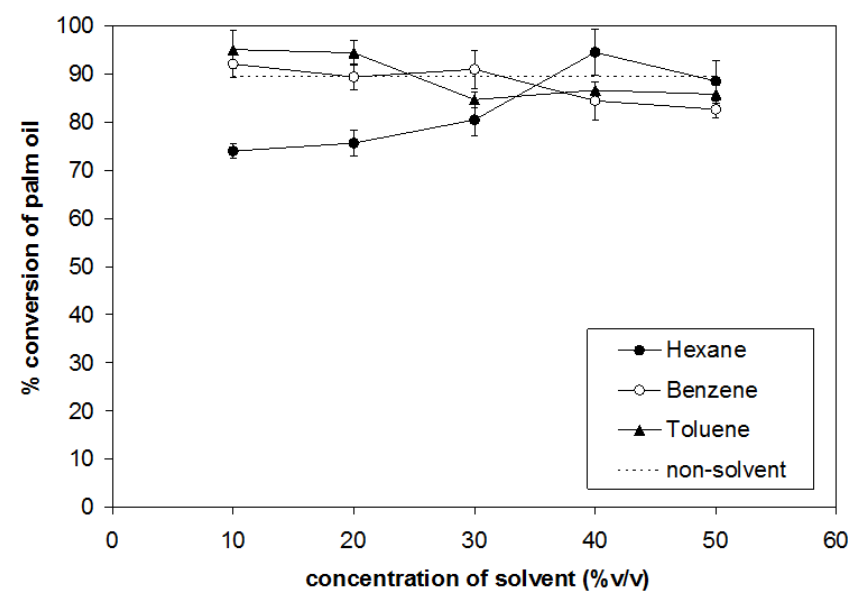

Fig. 4. Effect of concentration of co-solvent to palm oil, at molar ratio of methanol to palm oil molar ratio of $45: 1$ and $300^{\circ} \mathrm{C}$ and reaction time of $50 \mathrm{~min}$.

A different trend was observed when using hexane as the co-solvent. A significantly lower conversion of palm oil was observed in the presence of hexane. Nevertheless, the conversion increased with increasing hexane content (from 10 to 20,30 and $40 \% \mathrm{v} / \mathrm{v}$ and reached the maximum conversion at $94.5 \%$ when $40 \% \mathrm{v} / \mathrm{v}$ of hexane was applied. It is noted that, at $50 \% \mathrm{v} / \mathrm{v}$ of hexane, the conversion of palm oil suddenly dropped again. In general, hexane is soluble in oil but has low solubility in methanol; therefore, it acts as an antisolvent for vegetable oil in methanol and therefore reduced the biodiesel production yield. However, at high concentrations, hexane mixing of methanol with palm oil is significantly improved and the oil viscosity is significantly reduced. The decrease in viscosity leads to higher mass transfer between methanol and oil, thus increasing the product yield. The observed results from the present work are in accordance with the study by Dasari et al., 2003 [15], who reported that the concentration of hexane had an opposite effect on the biodiesel production. From this study, the optimum contents of benzene, toluene and hexane as co-solvents were found to be $10 \%, 10 \%$ and $40 \%$ $\mathrm{v} / \mathrm{v}$, respectively. These concentrations were then selected for later experiments.

\subsubsection{Effect of methanol to palm oil molar ratio (in the presence of co-solvents)}

The effect of the methanol to palm oil molar ratio on the conversion of palm oil via the transesterification process in the presence of a co-solvent (with 10\% v/v in oil for benzene and toluene, and $40 \% \mathrm{v} / \mathrm{v}$ for hexane) was studied by varying the methanol to palm oil molar ratio from 6:1 to 45:1. It is noted that the reaction temperature and the reaction time for these experiments were kept constant at $300^{\circ} \mathrm{C}$ and $50 \mathrm{~min}$. As shown in Fig. 5, the conversions of palm oil due to transesterification in the presence of co-solvent were significantly higher than those obtained without solvent, particularly at low methanol to palm oil molar ratios. Maximum conversions of 89.7 and $93.7 \%$ were obtained for the molar ratios 25:1 in the presence of benzene and toluene co-solvents. In the case of hexane co-solvent, the maximum palm oil conversion of $94.5 \%$ was obtained at the methanol to oil molar ratio of 45:1. Thus, it is concluded that by applying benzene or toluene as co-solvent, the requirement of excess methanol can be significantly reduced. 


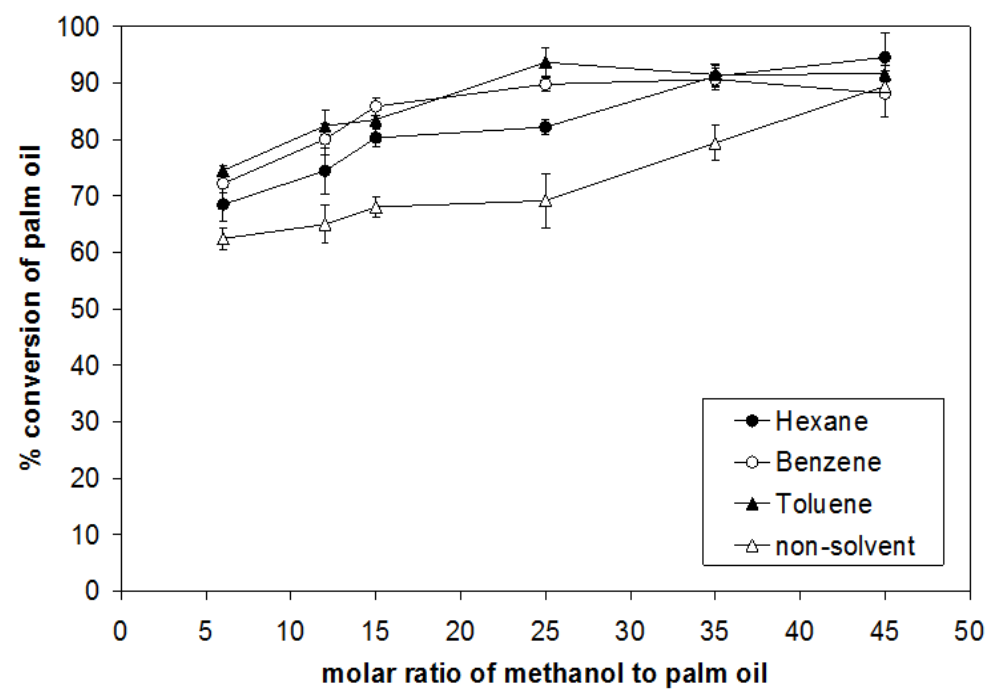

Fig. 5. Effect of molar ratio of methanol to palm oil on conversion of palm oil at $300^{\circ} \mathrm{C}$ and reaction time of $50 \mathrm{~min}$.

\subsubsection{Effect of reaction temperature (in the presence of co-solvents)}

Based on the optimum methanol to palm oil molar ratio and co-solvent concentration determined previously (25:1 for the transesterification with $10 \% \mathrm{v} / \mathrm{v}$ of benzene and toluene as co-solvents, and 45:1 for the transesterification with $40 \% \mathrm{v} / \mathrm{v}$ of hexane as co-solvent), the effect of the reaction temperature on the conversion of palm oil was then investigated by varying the temperature between 250,280 and $300^{\circ} \mathrm{C}$ (for a reaction time of $50 \mathrm{~min}$ ). Figure 6 presents the effect of temperature on the conversion of palm oil due to transesterification with and without benzene and toluene as co-solvents, while Fig. 7 presents results from reactions with and without hexane as a co-solvent. Figure 6 indicates that at low the temperature $\left(250^{\circ} \mathrm{C}\right)$, the presence of co-solvent does not show much impact on the reaction, whereas at higher temperatures $\left(280\right.$ and $\left.300^{\circ} \mathrm{C}\right)$, the use of benzene and toluene as co-solvent significantly improves the reaction performance. Figure 7 shows that by applying hexane as co-solvent, it inhibits the reaction at low temperature $\left(250\right.$ and $\left.280^{\circ} \mathrm{C}\right)$ and slightly improves the reaction performance at high temperature $\left(300^{\circ} \mathrm{C}\right)$.

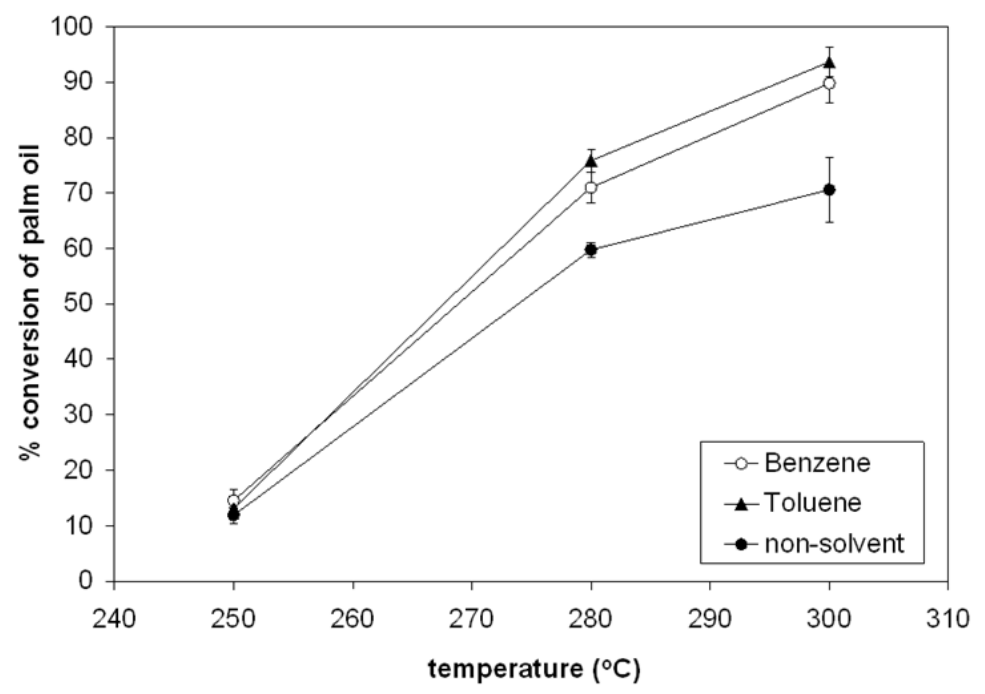

Fig. 6. Effect of temperature on conversion of palm oil at molar ratio of methanol to oil ratio of 25:1, $10 \% \mathrm{v} / \mathrm{v}$ solvent (benzene or toluene) to palm oil, and reaction time of $50 \mathrm{~min}$. 


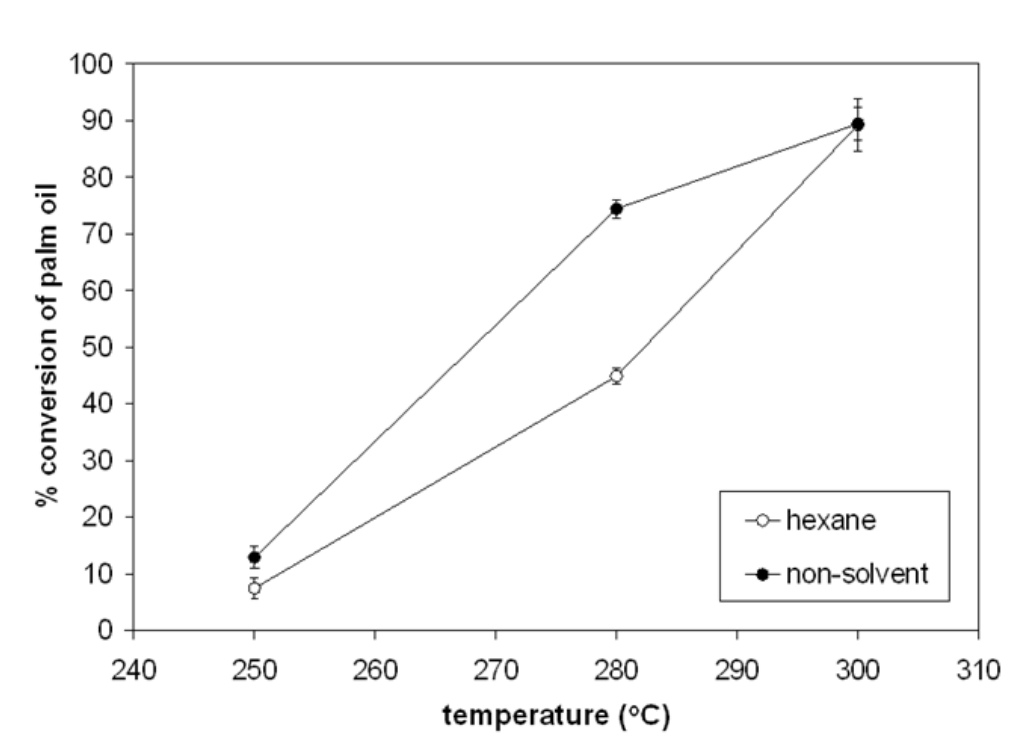

Fig. 7. Effect of temperature on conversion of palm oil at molar ratio of methanol to palm oil of 45:1, $40 \% \mathrm{v} / \mathrm{v}$ hexane to palm oil, and reaction time of $50 \mathrm{~min}$.

\section{Conclusions}

Methyl esters can be produced from the non-catalytic transesterification of palm oil in supercritical methanol at $300^{\circ} \mathrm{C}$ with a methanol to oil molar ratio of $45: 1$. The conversion of palm oil can be improved by adding either benzene or toluene (with $10 \% \mathrm{v} / \mathrm{v}$ solvent to oil) as a co-solvent. These cosolvents also help reduce the amount of excess methanol required (the methanol to oil molar ratio can be reduced from 45:1 to 25:1). At some conditions, the use of hexane as co-solvent can also increase the conversion of palm oil, but requires a high content of hexane (40\% v/v solvent to oil) must be added to the system and a high methanol to oil molar ratio (45:1), making it less favorable compared with the other solvents. For the future study, it is suggested that reaction at higher temperature be carried out as it could reduce the requirement of methanol substantially. In addition, the economics of use of cosolvent must be taken into consideration such that the cost of separation process in downstream must be recovered by the higher yield and production rate.

\section{ACKNOWLEDGEMENT}

The authors thank The Thailand Research Fund and Commission on Higher Education for financial support.

\section{References}

[1] M. Canakci and J. Van Gerpen, "Biodiesel production via acid catalysis," Transactions of the American Society of Agricultural Engineers, vol. 42, pp. 1203-1210, 1999.

[2] A. Srivastava and R. Prasad, "Triglycerides-based diesel fuels," Renewable \& sustainable energy reviews, vol. 4, pp. 111-133, 2000.

[3] H. Han, W. Cao, and J. Zhang, "Preparation of biodiesel from soybean oil using supercritical methanol and CO2 as co-solvent," Process Biochemistry, vol. 40, pp. 3148-3151, 2005.

[4] W. Cao, H. Han, and J. Zhang, "Preparation of biodiesel from soybean oil using supercritical methanol and co-sol vent," Fuel, vol. 84, pp. 347-351, 2005.

[5] S. Saka and D. Kusdiana, "Biodiesel fuel from rapeseed oil as prepared in supercritical methanol," Fuel, vol. 80, pp. 225-231, 2001.

[6] G. Madras, C. Kolluru, and R. Kumar, "Synthesis of biodiesel in supercritical fluids," Fuel, vol. 83, pp. 2029-2033, 2004.

[7] D. Kusdiana and S. Saka, "Kinetics of transesterification in rapeseed oil to biodiesel fuel as treated in supercritical methanol," Fuel, vol. 80, pp. 693-698, 2001. 
[8] M. Diasakou, A. Louloudi, and N. Papayannakos, "Kinetics of the non-catalytic transesterification of soybean oil," Fuel, vol. 77, pp. 1297-1302, 1998.

[9] E. S. Song, J. w. Lim, H. S. Lee, and Y. W. Lee, "Transesterification of RBD palm oil using supercritical methanol," Journal of Supercritical Fluids, vol. 44, pp. 356-363, 2008.

[10] B. Freedman, E. H. Pryde, and T. L. Mounts, "Variables affecting the yields of fatty esters from transesterified vegetable oils," Journal of the American Oil Chemists Society, vol. 61, pp. 16381643, 1984.

[11] S. Espinosa, T. Fornari, S. B. Bottini, and E. A. Brignole, "Phase equilibria in mixtures of fatty oils and derivatives with near critical fluids using the GC-EOS model," Journal of Supercritical Fluids, vol. 23, pp. 91-102, 2002.

[12] K. Bunyakiat, S. Makmee, R. Sawangkeaw, and S. Ngamprasertsith, "Continuous production of biodiesel via transesterification from vegetable oils in supercritical methanol," Energy and Fuels, vol. 20, pp. 812-817, 2006.

[13] W. B. Wan Nik, F. N. Ani, and H. H. Masjuki, "Thermal stability evaluation of palm oil as energy transport media," Energy Conversion and Management, vol. 46, pp. 2198-2215, 2005.

[14] K. Krisnangkura and R. Simamaharnnop, "Continuous transmethylation of palm oil in an organic solvent," Journal of the American Oil Chemists' Society, vol. 69, pp. 166-169, 1992.

[15] M. A. Dasari, M. J. Goff, and G. J. Suppes, "Noncatalytic alcoholysis kinetics of soybean oil," JAOCS, Journal of the American Oil Chemists' Society, vol. 80, pp. 189-192, 2003. 